\title{
ESTRANHAMENTOS E SURPRESAS: HÁBITOS ALIMENTARES NO CONTEÚDO DE ENSINO DE PORTUGUÊS LÍNGUA ESTRANGEIRA
}

\author{
Maria José Nélo ${ }^{1}$ \\ Aparecida Regina Borges Sellan ${ }^{2}$
}

\begin{abstract}
RESUMO: Este artigo discute estratégias de ensino tendo por focalização as necessidades essenciais de estudantes que visam aprender o português como língua estrangeira. Esses estudantes esperam obter conhecimentos linguísticos, enciclopédicos, sociointerativos plausíveis para o uso no cotidiano deles, por exemplo, designar, transformar os alimentos consumidos pelos nativos (maranhenses). Esses conteúdos sobre alimentos são, neste estudo, entendidos como um dado cultural e, para os falantes de outras línguas, uma oportunidade de compreender nosso sistema linguístico e de relação sociocultural para inserção no novo contexto. Os resultados demonstram que os falantes estrangeiros observados manifestaram menos estranhamentos linguísticos do que culturais, razão pela qual consideramos que significados culturais devem fazer parte dos conteúdos selecionados para o ensino de português língua estrangeira (PLE).
\end{abstract}

Palavras-chave: Ensino de PLE. Acolhimento. Designação. Alimentação. Cultura.

\section{STRANGEMENTS AND SURPRISES: EATING HABITS IN THE CONTENT OF TEACHING PORTUGUESE AS A FOREIGN LANGUAGE}

\begin{abstract}
This paper discusses teaching strategies focusing on the essential needs of students who aim to learn Portuguese as a foreign language. These students hope to obtain plausible linguistic, encyclopedic, socio-interactive knowledge for use in their daily lives, for example, nominate, convert the food consumed by the natives (Maranhenses). These contents about food are, in this study, understood as a cultural fact and, for speakers of other languages, an opportunity to understand our linguistic system and sociocultural relationship for insertion in the new context. The results demonstrate that the foreign speakers observed manifested less linguistic than cultural strangeness, which is why we consider that cultural meanings should be part of the selected contents for teaching Portuguese as a foreign language.
\end{abstract}

Keywords: Teaching of PLE. Refuge. Nominate. Alimentation. Culture.

\footnotetext{
1 Profa. Dra. da Universidade Estadual do Maranhão: marianelo@uol.com.br

${ }^{2}$ Profa. Dra. da Pontifícia Universidade Católica de São Paulo: borges@uol.com.br
} 


\section{Considerações iniciais}

Muito se tem discutido sobre questões culturais que envolvem o ensino de português língua estrangeira, talvez até mais do que a respeito do ensino geral de línguas estrangeiras. Acredita-se que tal preocupação decorra do fato de o ensino de português na qualidade de língua estrangeira ser bastante recente, nas últimas três décadas, mais especificamente. Talvez decorra também em razão de uma mudança de paradigma para o ensino de línguas estrangeiras ao colocar a cultura como aspecto tão relevante quanto a língua, em seu aspecto estrutural, pragmático e semântico. Isso porque, de acordo com Silveira (1998) ensinar língua é também ensinar a cultura impressa nessa língua.

Desse modo, este artigo está tematizado no conflito intercultural no ensino de português como língua estrangeira - PLE pelas designações dos alimentos e pelos hábitos alimentares responsáveis pelo estranhamento na interrelação e interação intercultural dos alunos em espaço de imersão de aprendizagem. Objetiva discutir, pelo viés intercultural, sobre o lugar da alimentação como conteúdo a ser tratado no ensino de PLE.

Tem por objetivos específicos: relacionar as estratégias para promover a interação entre os alunos de modo a identificar as dificuldades; levantar as informações relativas aos estranhamentos dos alunos focalizadas nas designações e nos hábitos alimentares dos brasileiros; confrontar as designações dos alimentos percebidas pelos alunos bem como os hábitos alimentares dos brasileiros com aspectos interculturais-brasileiros-estrangeiros; organizar atividades no processo de ensino-aprendizagem tendo como subtema a alimentação.

Justifica-se essa proposta ao considerar que ensinar português como língua estrangeira deve-se incorporar recursos que extrapolam as questões meramente linguísticas, uma vez que, para o estrangeiro, faz-se necessário explicitar os efeitos de sentidos implicados nas práticas inerentes aos fazeres próprios do grupo social cuja língua pretende aprender e por meio da qual necessita interagir. De acordo com Geraldi (2003)

é a linguagem que organiza o pensamento ( ou a consciência) e é significativa porque remete a um sistema de referências e somente neste sistema seus recursos têm sentido, e se este sistema de referências é, como propõe Franchi, produto e processo do trabalho constante da linguagem que se constitui ao mesmo tempo como língua (conjunto de recursos expressivos) e como sistema antropocultural de referências, já que este processo se dá, acontece no contexto sociocultural, então os 
estudos da linguagem, da língua, do pensamento e da cultura não podem distanciarse, sob pena de excluir elementos que lhe são próprios e constitutivos (p.80-81).

Justifica-se, ainda, quando, em contato com alunos estrangeiros, de origens variadas - sulamericanos e africanos - interessados em aprender a língua portuguesa, identificou-se a dificuldade de esses alunos alimentarem-se com produtos nacionais e regionais disponíveis, em São Luís, MA, os quais eram distintos daqueles de suas regiões de origem. Alguns desses alunos limitaram-se a consumir apenas bolachas e água com receio de adoecerem pela ingestão de alimentos desconhecidos.

Outros alimentavam-se com tudo que lhes fosse oferecido, ainda que não identificassem a origem, o tipo e a substância. Nesse sentido, fez-se necessário criar unidades componenciais de aula que focalizassem o tema "alimentos". Sobre esses procedimentos passaremos a tratar.

\section{1- $O$ contexto da pesquisa}

O conjunto de alunos, cuja experiência será discutida neste artigo, é composto por estudantes que chegaram ao Brasil com a finalidade de se afastarem dos problemas enfrentados em seus países, sendo enquadrados em situação de acolhimento. Foram organizados em dois grupos de acordo com a aproximação ou o distanciamento de suas línguas em relação ao português brasileiro. Entre eles, havia venezuelanos, colombianos e africanos. Para os dois primeiros, de língua hispânica, a relação com a língua portuguesa foi considerada língua de proximidade; para o terceiro, falantes de diversas línguas africanas, essa relação foi considerada línguas de distanciamento.

Na organização dos grupos já se observava a diversidade não apenas relativa às questões de língua dos grupos, mas, e talvez principalmente, relativa à cultura - aqui compreendida em sentido plural, como produto de realizações materiais e imateriais dos grupos sociais. Entre essas realizações, de forma inesgotável, estão as vestimentas, as músicas, as pinturas e esculturas, os hábitos de convívio social e a alimentação.

Devemos entender a cultura como valores relativos ao vivido e ao experienciado em sociedade. Esses valores têm raízes históricas e vão sendo modificados e atualizados de acordo com a realidade contemporânea de seus grupos sociais. Como valores culturais, são, ainda, transmitidos de geração para geração, de forma a construir normas e atitudes que guiam as pessoas ao se relacionarem com o mundo, sem o objetivo da discriminação. Os valores culturais implicam 
ideologias. Tanto os valores ideológicos quanto os culturais são dinâmicos, pois, em cada contemporaneidade, há problemas novos a serem resolvidos em outra situação cultural. Os valores culturais têm uma dinâmica resultante de novas necessidades a serem supridas; dessa forma, recorre-se ao que está atualizado para propor o diferente/o novo.

Segundo Silveira (2008), a diferença entre ideologia e cultura decorre dos valores que compõem as formas de conhecimentos. A ideologia impõe uma escala de valores decorrentes dos interesses da classe de poder; esses valores têm por intenção discriminar as pessoas. Já cultura constitui-se de valores vividos e transmitidos pelos participantes de um grupo social. Nesse sentido, devemos considerar que o fato de os alunos aqui estudados apresentarem diferenças e estranhamentos decorrentes de seus hábitos e do que foi vivido e experienciado em seus contextos de origem, não deve ser motivo nem de discriminação nem de dificuldades de aprendizagem da nova língua. Por essa razão, cabe ao docente a sensibilidade de perceber os entraves de interação e relacionamentos inter e extra grupais e criar estratégias de socialização que promova a motivação para o aprendizado.

Não há dúvidas de que o contexto criado com a reunião desse grupo de alunos é multicultural e multi-ideológico. Todos tinham necessidade de inserção e adaptação ao novo. E o elemento imprescindível para que essa 'adaptação' fosse concretizada seria mediante o aprendizado da língua. O que os mantinha unidos era a condição de expatriados, normalmente pelas mesmas razões e, desse modo, era-lhes atribuída alguma identidade.

\section{2 - A situação vivenciada}

O desenvolvimento das aulas com esse grupo de alunos seguiu uma orientação geral no sentido de ajudá-los a se situarem no novo ambiente. Por isso, as orientações de identificação pessoal e dos colegas, escolaridade, profissão ou função que desempenhavam em seus países, reconhecimento dos espaços por onde eles circulavam com frequência, entre outras estratégias utilizadas com o objetivo de integrar os grupos. A princípio, funcionou como um "quebra-gelo", permitindo os primeiros movimentos, muito tímidos, de interação, mas que ainda não gerava integração nem contribuía para a evolução do aprendizado.

Desse modo, decidimos usar outras estratégias, que estimulassem a participação de todos os alunos. Passamos a fazer perguntas; por exemplo, sobre qual foi seu primeiro estranhamento ao 
chegar no Brasil? Esse foi um gatilho importante e, por unanimidade, os alunos disseram: a comida. Indagados sobre o porquê desse estranhamento, as respostas deram vários direcionamentos. Para eles, o diferencial não estava nos momentos de refeições - café, almoço e jantar, designações das principais refeições diárias do brasileiro; o impacto sucedia da constante repetição dos alimentos: arroz, feijão e carne no almoço e no jantar; outros não compreendiam a designação dos pratos, das frutas, dos frutos. Intrigavam-se, ainda, com o modo de servir a comida; isto é, o modo de transformação dos alimentos in natura em cozidos, assados ou fritos, transformados em caldo, ou em calda.

Esse conjunto de informações foi extremamente importante para orientar o redirecionamento de nossas aulas. As “conversas” sobre hábitos alimentares, alimentação, tipos de alimentos passaram a estimular o interesse dos alunos e esse foi o grande mote para os encaminhamentos futuros.

Aproveitamos para explicar que, de fato, há preferências alimentares, a princípio, atribuídas a uma possível identificação do brasileiro. Entretanto, com alguma breve pesquisa, podemos comprovar não serem exclusivas para todos nem uma constante, pois há grande variedade de comidas "típicas" que diferenciam a predileção dos brasileiros por certos alimentos desde a maneira de sua colheita, cozinhar, combinar, preparar, temperar e servir, dependendo, inclusive, da região brasileira modifica-se o seu uso. O preparo de alguns alimentos entre os brasileiros pode se diferenciar de acordo com as seguintes situações: como, quando, para quem, em que circunstância são degustadas.

Esses indicadores foram essenciais para tratarmos de um conjunto de conhecimentos que pudessem ser acessados pelos alunos, considerando diferentes dimensões comunicativas, seja na relação "eu/tu”, seja na relação "eu/texto". Para tanto, selecionamos estrategicamente textos que trouxessem em sua materialidade designações de alimentos, indicadores da culinária e de pratos específicos para construir novos referentes, capazes de propiciar, em especial para nossos interlocutores, conhecimentos relativos ao conjunto de palavras responsáveis por designar os alimentos responsáveis por promover estranhamento. Destacamos que as palavras não designam apenas referentes, amalgamam narrativas capazes de representar conhecimentos sociais, sendo essas cultuadas e propagadas por crenças, saberes e fazeres que, simultaneamente, estão 
condensados em palavras, com conteúdo definido, que se remetem a modelos situacionais diferentes na memória cognitiva do brasileiro, os quais podem e devem ser explicitados nas aulas de PLE.

Estrategicamente, apresentamos aos alunos textos cujos conteúdos remetiam-se a alguma ocorrência com alimentos. Sugerimos a leitura de textos que favorecessem a participação de todos, mesmo daqueles que demonstravam pouco domínio do português. Eles deveriam identificar as palavras desconhecidas e, nas aulas seguintes, usariam celular para auxiliar a busca de significação das palavras e/ou imagens dos alimentos, comidas e pratos por eles selecionadas.

Além das atividades com a leitura de textos e a busca das palavras e/ou expressões que se ligassem à alimentação, os alunos foram orientados a realizarem passeios pela cidade, em mercados, restaurantes, pontos de vendas de comidas em espaços públicos, calçadas, semáforos e festas.

Nossa pretensão era promover condições para os alunos participarem das aulas, tendo identificado, nessas atividades, objetos que pudessem ser motivo de "conversas" e, por consequência, aprendizado. No entanto, essas estratégias permitiram um alcance mais amplo, pois observamos o desenvolvimento de outras competências além da comunicativa, como interesses pela escrita alfabética portuguesa, pela oralização das palavras e expressões, percepção cultural e intercultural, intragrupo e extra grupo, uma vez que, concomitantemente, comparavam e tratavam de suas culturas, seus hábitos e costumes, suas crenças. Dessa forma, as palavras que designam alimentos, comidas e culinária, antes desprovidas de significados referenciais para eles, passaram a constituir sinalizações significativas para os interlocutores construírem referentes, significados e sentidos.

Essas ações ora de incentivo de conversação, ora de produção escrita, ora de pesquisa no dicionário on-line online, tornaram a prática de sala aula interativa, atravessada por outros discursos, especialmente se considerarmos os textos utilizados nas aulas como espaços de trocas e compreensão das práticas narrativas, históricas, culturais representadas nas formas dos hábitos alimentares identificados e estudados. Foi o que verificamos nos textos, nas palavras e expressões enunciativas que os alunos destacaram. Para mantermos a unidade sobre conteúdos focalizados na alimentação, direcionamos a atenção para as designações de frutas, pratos, caldos, caldas e, 
respectivas, narrativas sobre esses alimentos, ocorrendo a trocas sobre crenças, costumes e hábitos que fazem um povo se aproximar ou se distanciar uns dos outros.

\section{3- Propostas de atividades}

Com o propósito de viabilizar o contado dos alunos com elementos que, de algum modo, estão presentes na alimentação do maranhense, porque este é o locus em que os alunos estão convivendo, selecionamos diferentes textos que trouxessem referências à alimentação. Assim, apresentamos a letra da música "Todos Cantam Sua Terra", de autoria de João do Vale, conforme, adaptação de parte do texto para que os alunos, auxiliados pelo professor e alguns estagiários, destacassem as palavras referentes às frutas. Após, foram orientados a usar o celular para identificarem imagens que pudessem auxiliá-los a reconhecer as frutas e compreender seus significados.

\begin{tabular}{|c|c|}
\hline $\begin{array}{l}\text { Todos Cantam Sua Terra } \\
\text { João do Vale } \\
\text { Todo mundo canta sua terra } \\
\text { Eu também vou cantar a minha } \\
\text { Modéstia à parte seu moço } \\
\text { Minha terra é uma belezinha } \\
\text {............................ }\end{array}$ & $\begin{array}{l}\text { E fruta lá tem: juçara } \\
\text { Abricó e buriti } \\
\text { Tem tanja, mangaba e manga } \\
\text { E a gostosa sapoti } \\
\text { E o caboclo da maioba } \\
\text { Vendendo bacuri } \\
\text { Tinha tanta coisa pra falar } \\
\text { Quando estava fazendo esse baião } \\
\text { Que quase me esqueço de dizer } \\
\text { Que essa terra é tão linda é o Maranhão } \\
\text { Ô Maranha, ô Maranhão. }\end{array}$ \\
\hline
\end{tabular}

Fonte: Letra de João do Vale. https://www.letras.com.br

Como se pode observar, a letra da música apresenta um conjunto significativo de frutas comuns nas feiras, nos mercados, nas casas dos moradores de São Luís -MA, pois são frutas típicas dessa região do Brasil. O próprio contexto da música favoreceu a identificação dos nomes das frutas e o professor teve de conduzir a atividade de modo a explicitar aquilo que não era possível apenas com o acesso ao celular. Foi necessário, por exemplo, explicitar que algumas frutas são sazonarias, por isso, ao fazerem um passeio pelo mercado público, foi possível que eles degustaram o doce de buriti. Naquela ocasião um dos alunos, do Senegal, fez a seguinte observação "por que as comidas são vendidas no espaço interno do mercado ${ }^{3}$ ?" O referido aluno enfatizou que "na nossa

\footnotetext{
${ }^{3}$ A pergunta do aluno nos surpreendeu, a todos nós brasileiros, para amenizar o inesperado, respondemos para proteger os alimentos dos ventos e poeira.
} 
cultura vende-se "tudo junto e misturado"”. A pesquisa realizada pelos alunos sobre as frutas permitiu que chegassem ao seguinte quadro de definições:

Abricó - nome científico Mammea americana, esse alimento ainda recebe o nome de abricote ou abricoteiro, sendo carnoso e de formato redondo. O abricó é mais consumido nos Estados Unidos e, aqui no Brasil, é comum no estado do Pará.

Buriti - fruta do buritizeiro de ampla distribuição no território nacional. A espécie habita terrenos alagáveis e brejos de várias formações, sendo encontrada como frequência nas veredas, importante fitofisionomia do Cerrado. O buriti floresce quase o ano inteiro, principalmente nos meses de abril a agosto.

Tanja - Tangerina, mexerica, laranja-cravo, bergamota, poncã (ou ponkan). Poncãs e mexericas são duas variedades da tangerina. A mexerica atende por vários nomes: bergamota no Rio Grande do Sul, mimosa para os curitibanos e tanja para o pessoal do Piauí e Maranhão.

Mangaba - árvore rústica típica do bioma Caatinga, mas pode ser encontrada em fisionomias do Cerrado. Também bastante comum no litoral do Nordeste.

Sapoti - cujo nome científico é Manilkara zapota, pertence à família Zapotaceae. É uma fruta muito saborosa, proveniente da América Central, foi espalhada para outros continentes. É encontrada em países como Guatemala, Jamaica, Filipinas, Indonésia, Venezuela, Suriname dentre outros. No Brasil, é encontrado principalmente nas regiões norte e nordeste, como nos estados de Pernambuco, Paraíba e Rio Grande do Norte em razão destas localidades possuírem clima tropical, quente e úmido ou seco, favorável ao seu crescimento.

Bacuri - tem origem tupi e significa "cai logo", característica marcante do fruto que se desprende da planta logo que amadurece, normalmente entre os meses de janeiro a junho.

O segundo texto apresentado aos alunos foi também a letra de uma música cantada por um dos grupos "folclóricos", representante de uma toada de Bumba Meu Boi, festa ou brincadeira de entretenimento de expressão cultural popular, ocorrente durante a festa regional chamada "Festas Juninas ou de São João". Nessas festas, é celebrada a fartura da colheita de grãos; por essa razão, são servidas não apenas comidas diversas elaboradas com os produtos colhidos, bem como bebidas, tais como a cachaça, feita com a cana de açúcar, e a tiquira, feita de mandioca.

A letra da música tematiza um dos valores culturais maranhenses centrado na gastronomia - o arroz de cuxá. A canção tem por título "Cuxá Orquestrado", cujo autor é Wellington Reis, conforme abaixo: 


\begin{tabular}{|c|c|}
\hline Cuxá Orquestrado & Cuida, menina etc... \\
\hline Wellington Reis & Camarão seco, do Maranhão \\
\hline Cuida menina & (trezentos gramas é suficiente) \\
\hline vai pro pilão & Deixa de molho na água fria. \\
\hline Tem que socar com a mão. & Bota de noite, tira de dia. \\
\hline Se não tiver pilão, meu amor, & \\
\hline Vai no liquidificador! & $\frac{\text { Farinha seca de mandioca }}{\text { Tudo socado, como paçoca }}$ \\
\hline Um maço de vinagreira & Leva pro fogo e tem que molhar \\
\hline (Só as folhas escaldadas) & Mexendo sempre até engrossar. \\
\hline Duas cebolas vermelhas descascadas e picadas. & Se a língua aguenta, \\
\hline Gergelim preto, torrado & Por que não bota pimenta? \\
\hline $\mathrm{Na}$ frigideira e bem socado & \\
\hline São três colheres do pó & \\
\hline Pro cuxá ficar melhor. & \\
\hline
\end{tabular}

Fonte: $O$ sotaque maranhense $:^{4}$ a arte de cozinhar - CD de Wellington Reis e José Ignácio, 2002.

O arroz de cuxá é de origem maranhense, um tipo de molho feito com vinagreira (planta muito encontrada no Maranhão), diferentes especiarias (como o pimentão) e farinha de mandioca - ingrediente que constituía a base da alimentação dos índios. O nome cuxá, inclusive, vem do tupi e significa "o que conserva azedo". É alimento rico em vitaminas e antioxidantes, sendo ótimo para fortalecer a imunidade e conceder mais sabor aos diferentes pratos. A maioria das receitas de cuxá também envolvem camarão seco - outro ingrediente do Maranhão.

Como dissemos anteriormente, entre as causas dos estranhamentos relatados pelos alunos sobre os hábitos alimentares observados estava a repetição do arroz e feijão nas refeições principais, almoço e jantar, por exemplo. O contato com essa canção e ao perceberem que ela traz uma espécie de receita do prato, eles ficaram curiosos por saber o que seria a "vinagreira", pois, num primeiro momento, não foram capazes de associar a qualquer conhecimento prévio que situasse essa iguaria. Importante destacar que alguns elementos presentes nesses versos foram rapidamente identificados, principalmente pelos africanos, por meio de gestos ou aproximações com palavras que associavam ao português, por exemplo, pilão, camarão seco, os temperos,

\footnotetext{
${ }^{4}$ De acordo com Sanches (2003) o termo sotaque significa, para alguns, os estilos de Bumba-meu-boi que variam a partir das indumentárias, dos instrumentos, da melodia, do ritmo, do canto e da dança. Para outros, significa a característica individual de cada grupo de Boi, ou seja, cada grupo tem um sotaque que lhe é peculiar. Já para os brincantes, é sinônimo de ritmo.
} 
paçoca, até mesmo o gergelim. Mas a vinagreira, essa planta somente foi entendida quando conseguiram associá-la ao hibisco. É atribuída à África Oriental e à Ásia a origem dessa planta, cujos efeitos medicinais têm sido bastante difundidos. Talvez por essa razão, os alunos se mostraram receptivos para o prato "arroz de cuxá". Outra observação importante é o fato dessa iguaria ser servida "tudo junto e misturado", provocando certa similitude com o modo de servir alimentos, especialmente entre os africanos. $\mathrm{O}$ arroz de cuxá acabou se tornando um elo de identidade entre os alunos e os maranhenses e, a partir desse conhecimento, eles passaram a se interessar mais pelos nossos alimentos e nosso modo de organizar, combinar, juntar, servir, distribuir os alimentos num mesmo prato e em diferentes refeições.

Conforme já dissemos, a organização da aula de PLE pautada na troca intercultural promove integração entre professor e alunos, na medida em que as duas partes ganham conhecimentos e/ou tomam consciência de sua própria realidade cultural. A título de exemplificação sobre a culinária africana, os alunos disseram que, de acordo com os hábitos deles, tudo é cozido em uma só vasilha, ou seja, grãos, carnes, legumes, verduras são postos na panela de acordo com a ordem de duração do cozimento; no momento que a comida está pronta para ser servida, a primeira pessoa a experimentar é quem cozinhou, para comprovação de que a comida está adequada para ser consumida, além evitar envenenamento.

Geralmente, as refeições são coloridas para despertar ainda mais o paladar. Há também preferência de comerem em um prato grande e sem talheres. Eles comem no mesmo prato, levam os alimentos com as pontas dos dedos para a boca como prova de acolhimento e familiaridade entre os comensais. Porém, se há algum visitante na comunidade, eles oferecem talheres e o visitante é servido pelo dono da casa, nunca deve ser servido pelas mulheres.

\section{4- Algumas reflexões}

Nosso estudo tem por ponto de partida que tratar da alimentação, dos hábitos alimentares, das especificidades culinárias no ensino de língua é um importante viés que pode não apenas sensibilizar o aluno para o aprendizado da nova língua como também conscientizá-lo dos aspectos culturais e interculturais implicados em todo o processo.

Desde o Brasil colonial, há estudos sobre literatura e culinária, os quais privilegiam histórias pertencentes a contextos sócio-históricos específicos de escolas, correntes literárias ou documentação histórica sobre costumes, hábitos e modos de o povo brasileiro transformar os 
alimentos in natura em comida de cotidiano. Escritores de períodos literários dos "viajantes à atualidade", não deixam de arrolar em suas narrativas os registros sobre comidas, festividades, quem faz a comida, como é servida, o que pode ou não ser ingeridos, conforme crenças e religiosidades. Essas práticas estão catalogadas não só como manifestação cultural popular, científica, mas também literária em romances, crônicas, poemas, tal como se observa nas pesquisas realizadas por Queiroz (1994), Frieiro (1982), DaMatta (1998) Câmara Cascudo (2004). Esses estudiosos convertem informações sobre a culinária em arte culinária e forma de transmissão de saberes e fazer do povo brasileiro. Não que sejam estudos específicos para o ensino de língua portuguesa para nativos, menos ainda para estrangeiros, mas pode-se atentar para uma ou outra tangibilidade para sequenciar informações de hábitos e costumes alimentares e tipologia textual, que se tornam muito pertinentes para o ensino de língua-cultura.

Nos estudos de Queiroz (1994), a culinária é situada nas obras literárias portuguesa e brasileira, do século XIX. Nesse período, a mesa brasileira se relaciona com a portuguesa, de Eça de Queirós à Machado de Assis, Aluísio Azevedo e Graça Aranha. No século XX, a escritora Rachel de Queiroz trata da culinária no meio rural; Mário de Andrade retrata a arte da gastronomia no Movimento Modernista; O Banquete da mesa nordestina, de José Lins do Rego, complementa com "A festa do apetite" nos romances de Jorge Amado, e "O tempo e o vento" de Érico Veríssimo.

Apesar de os estudos realizados por Queiroz (1994) direcionarem-se à antropologia e sociologia pelos vieses da culinária incrustada na literatura, pode-se atribuir à literatura meio ativo de possibilidades de leituras, em que o leitor produz sentidos do texto ao decifrar palavras, costumes, hábitos, entretenimentos, crenças e percebe as ideias pela visão do outro e do que ele constata no dia a dia.

Nesse contexto de aspectos relativos à literatura e à culinária, Frieiro (1982) considera ambas como artes. A primeira, por armazenar os saberes e fazeres em memórias escritas; a segunda, como nona arte, por transformar comidas e alimentação por práticas profissionais. Esses, por sua vez, são guiados por crenças e tradições nos modos de transformar alimentos in natura em comida e, ainda, recorrem às influências de novos hábitos das cozinhas estrangeiras francesa, italiana, inglesa, todas colocadas na mesma panela na formação dos sabores da culinária brasileira. Frieiro (1982) entende que a literatura constitui fios da história sociocultural dos diferentes povos constituintes da miscigenação brasileira, tendo por suporte prosas e poemas de escritores brasileiros e estrangeiros. 
O sociólogo-antropólogo DaMatta (1998) coloca os ingredientes dessa discussão literária e não literária na a casa, a rua e no trabalho sobre comidas, mulheres, entre outras situações, para refletir sobre "O que faz o brasil, Brasil?”. Ao fazer referência aos alimentos crus, o autor menciona que "o cru se liga a um estado natural, ao passo que o cozido se relaciona ao universo socialmente elaborado que toda sociedade humana define como sendo de sua cultura e ideologia" (p.52). Essa constatação sublinha a primazia de integrar os fatores relacionados à comida como estratégia de promover e permitir pensar o mundo sensorialmente, partir da leitura da palavra à leitura de mundo (FREIRE, 1989), sem se adotar a leitura como manual de instrução, mas como fonte de múltiplos saberes e fazeres. O importante é conhecer a cultura do outro e respeitar o diferente e as diferenças de uma e de outra cultura. Assim sendo, justifica-se integrar o ensino de língua, de literatura e de cultura nas aulas de PLE.

A compilação dos víveres alimentares, modo de plantar, colher, fazer e partilhar os comensais entre brasileiros e estrangeiros desde a ocupação do território brasileiro encontra-se no acervo inventariado por Cascudo (2004), em História da alimentação do Brasil, nesse documentário constitui de outras informações relevantes sobre a mistura da cozinha local com as de outros povos, aqui se mesclam e se reinventam.

Portanto, a literatura e antropologia, se bem explorada e relacionada a conhecimentos de mundo e às demais disciplinas, além da língua portuguesa, pode ser um recurso para atrair a participação dos aprendizes e, ao mesmo tempo, auxiliar reflexões sobre elementos primários que integram parte das necessidades alimentares e intelectuais da capacidade humana e, assim, por meio da construção de sentidos transformar sua realidade, dialogar com "outros" textos, culturas e grupos sociais diferentes.

Com essa concepção dialógica e intercultural, confirma-se o texto como lugar das interações e "como objeto multifacetado, construído nas dinâmicas interativas em que sujeitos constroem sentidos e meio de materialidades linguísticas, elaborações cognitivas de conhecimento e práticas sociais de uso da língua" (KOCH, ELIAS, 2016, p. 31). Assim, o texto sintetiza uma série de códigos culturais, normalmente tratados em separado: agrupamento social, crença, ideologia, valores, espaços domésticos, manifestações culturais, literatura, posição dos membros da família em casa e em público, esses detalhes quase sempre estão em único texto.

A leitura de texto poético possibilita mediação, conforme Sant'Anna (2009) promove interlocução do poético com o texto e com o leitor. Em tal condição, deve o leitor decidir seu 
envolvimento; já, o poeta usa estratégias de provocações para um público heterogêneo, os efeitos positivos emergem de ações provocadoras, das formas poéticas usadas para seduzir os leitores.

Do cenário literário ao ensino de língua portuguesa e cultura para falantes de outras línguas, encontra-se Almeida Filho (2011), para quem essa modalidade de ensino "existe como prática no Brasil desde o seu início colonial” (p. 93), embora, nesse percurso, tenha-se privilegiado a apreensão sistemática de estruturas linguísticas e respectivas normas gramaticais. O ensino PLE deve ainda abarcar sistema de crenças, saberes, normas, técnicas, hábitos formulados e partilhados historicamente, na e pela linguagem verbal e não verbal, constituído como fator identitário do país, comunidade ou grupo social.

Com ideias similares sobre o ensino de língua e cultura, Silveira (2004) versa que a cultura é um "conjunto de tradições e valores que guiam as atitudes das pessoas e pode constituir respostas para seguintes indagações: quem somos, quem você é, quem ele é, o que pensamos que somos e o que queremos ser?” (p. 152). São essas questões causadoras de embate para a seleção e aplicação do material didático em aula PLE. De um lado, situam-se às dúvidas do regente das aulas; do outro, as expectativas e os conflitos dos alunos.

Não obstante, a realização de leituras em aulas de PLE como prática de ensino são imprescindíveis para os alunos. Para Silveira (2000, 2004), a cultura é uma forma de identificação, isto é, implica uma identidade social a qual se constrói, cognitiva e socialmente, mediante as experiências dos sujeitos, ao atribuírem sentidos ao mundo social e interagirem entre si. A significação é relativa ao mundo e seus acontecimentos e é compartilhada por consenso pelos membros de uma mesma comunidade: "pode-se dizer que a identidade cultural de um país é um modo de ser nacional, ainda que haja variedades/variações culturais específicas de cada grupo", (SILVEIRA, 2000, p. 21).

\section{Considerações finais}

Tivemos por objetivo tratar, pelo olhar intercultural, do ensino de português língua estrangeira focalizando, como conteúdo a ser ensinado, a alimentação. Consideramos, a princípio, que a resistência apresentada pelo aluno estrangeiro, nos primeiros contatos com a nova língua, resultou de estranhamentos culturais que precisavam ser identificados. Desse modo, relatamos, além das estratégias de identificação dos possíveis estranhamentos observados em um grupo de alunos específicos, o encaminhamento de atividades que se mostraram eficazes e estimuladoras 
para a aproximação e interação dos e entre os alunos, de modo a permitir que o aprendizado se realizasse. Observamos que tratar do tema alimentação, bem como dos diferentes hábitos tanto de preparo como de consumo dos alimentos foi extremamente valioso para todos, uma vez que o elemento cultural perpassou por todo o processo.

A cultura exprime precisamente um estilo, um modo e jeito de fazer coisas (cf. DaMatta, 1998). Nessa concepção do antropólogo, situamos o ensino de PLE, pois consideramos uma unidade na diversidade cultural dos grupos sociais. A possibilidade de encontrar uma unidade extra grupal foi demarcada pela designação lexical da culinária maranhense no âmbito brasileiro (SILVEIRA, NÉLO, 2002). Por conseguinte, os textos das letras musicais possibilitaram o estudo lexical, leitura, construção de sentidos, de modo que os aprendizes foram capazes de transformar sua realidade em textos orais e escritos.

Quanto ao funcionamento de leitura - em especial a literária representada nas letras musicais -, Sellan e Cury (2018) retomam Takahashi (2014), que considera três elementos “[...] no discurso literário e seu lugar social no ensino de uma língua estrangeira: a instância do autor, a do texto e ado leitor". Consecutivamente, o autor capta, explícita e focaliza opinativamente sua visão de mundo; o texto condiciona e viabiliza a conexão entre fatos linguísticos e extralinguísticos na interlocução entre autor e leitor; o leitor constitui o agente da compreensão. Pelos elementos do texto, o leitor aciona seus saberes prévios e completam o diálogo textual do autor.

Assim, os textos foram essenciais nas aulas de PLE, para conduzir os leitores pelos caminhos das crenças, saberes, normas, técnicas, hábitos formulados e partilhados historicamente, na e pela linguagem verbal e não verbal.

\section{Referências Bibliográficas}

ALMEIDA FILHO, J. C. P. Fundamentos de abordagem e formação de PLE e de outras línguas. Campinas, SP: Pontes, 2011.

CASCUDO, L. C. História da alimentação no Brasil. 3. ed. São Paulo: Global, 2004.

DAMATTA, R. O que faz o brasil, Brasil? 9. ed. Rio de Janeiro: Rocco, 1998.

FREIRE, P. A importância do ato de ler, em três artigos que se completam. 23. ed. São Paulo: Cortez, 1989. (Coleção Polêmicas de Nosso Tempo).

FRIEIRO, E. Feijão, angu e couve. Belo Horizonte: Ed. Itatiaia; São Paulo: Ed. Universidade de São Paulo, 1982.

GERALDI, J. W. Portos de passagem. São Paulo: Martins Fontes, 2003. 
KOCH, I. G. V.; ELIAS, V. M. O texto na linguística textual. In: BATISTA, R. O (Org.). O texto e seus contextos. São Paulo: Parábola, 2016. (p. 31-44).

QUEIROZ, M. J. A literatura e o gozo impuro da comida. Rio de Janeiro: Topbooks, 1994.

SANCHES, A. S. O universo do Boi da Ilha: um olhar sobre o bumba-meu-boi em São Luís do Maranhão. 2003. Dissertação (Mestrado em Antropologia) - Universidade Federal de Pernambuco, Recife. 192 p.

SANT'ANNA, A. R. A poesia e os mediadores de leitura. In: SANTOS, F. et al. (Orgs.). São Paulo: Global, 2009. p. 157-170.

SELLAN, A. R. B.; CURY, V. F. Fabianos, Sinhás Vitórias: a literatura no ensino de português língua estrangeira. In: BASTOS, N. B. (Org.). Língua portuguesa: história, memória e intersecções lusófonas. São Paulo: Educ, 2018. p. 185-196.

SILVEIRA, R. C. P. Implícitos culturais: ideologia e cultura em expressões linguísticas do português brasileiro. In: BASTOS, N. B. (Org.). Língua portuguesa em calidoscópio. São Paulo: EDUC, 2004. p. 143-158. (Série Eventos).

- Opinião, marco de cognições sociais e a identidade cultural do brasileiro: as crônicas nacionais. In: JÚDICE, N. (Org.). Português / língua estrangeira: leitura, produção e avaliação de textos. Niterói: Intertexto, 2000. p. 9-35.

. (Org.). Português Língua Estrangeira: perspectivas. Cortez: São Paulo, 1998.

. Sociedade. Sociedade, cognição e discurso: conhecimentos sociais. In: BASTOS, N. (Org.). Língua portuguesa: lusofonia memória e diversidade cultural. São Paulo: EDUC, 2008. p. 109-122.

SILVEIRA, R. C. P.; NÉLO, M. J. Discurso e expressões linguísticas do português brasileiro: aspectos histórico-culturais nas designações da culinária brasileira. Taubaté-SP, 2002. (Comunicação GEL).

Takahashi, N. T. Leitura literária em português língua estrangeira (PLE): representações, compreensão e produção textual. 2014.Tese (Doutorado) - Universidade de São Paulo, São Paulo. 